
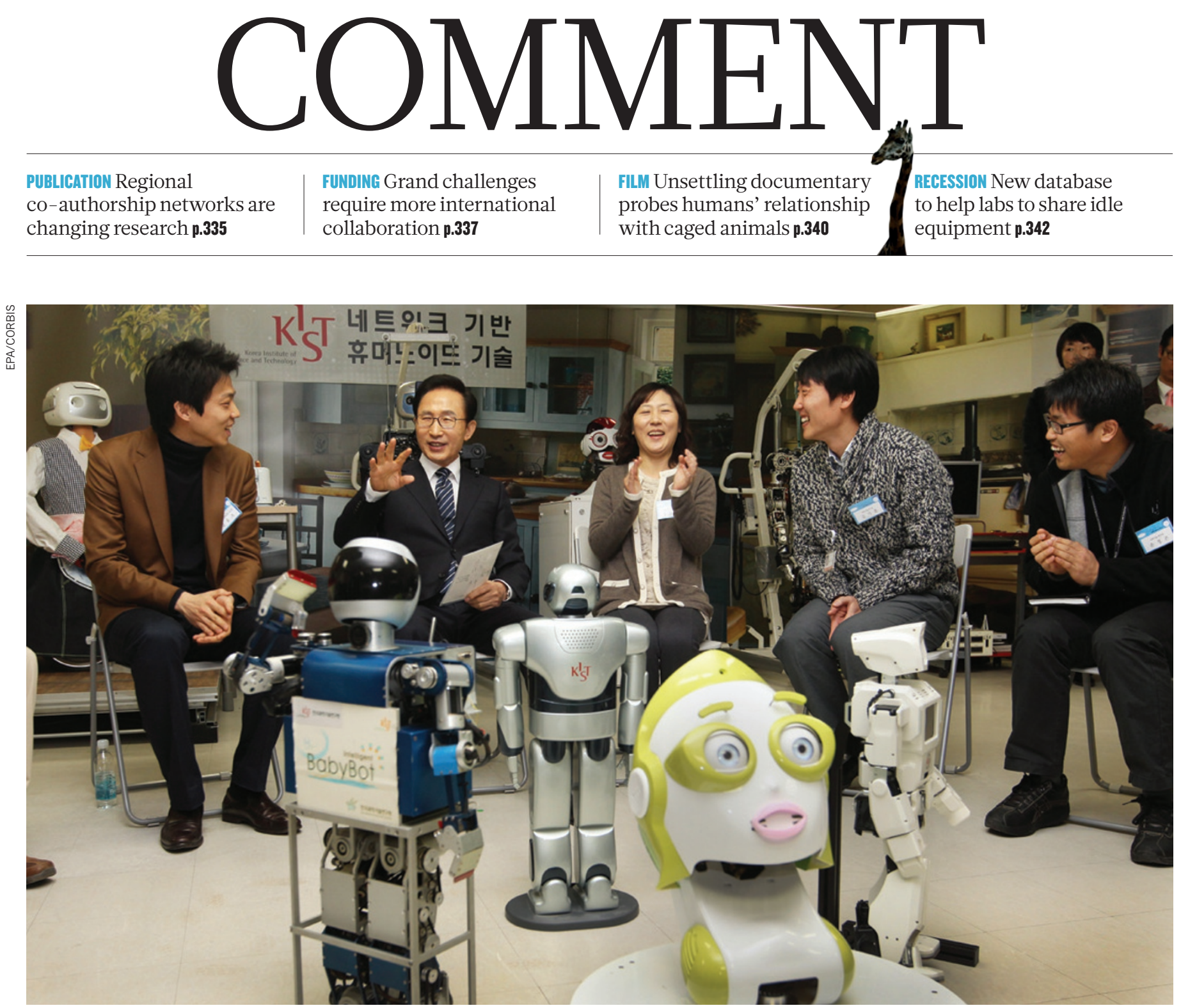

South Korean President Lee Myung-bak (second from left) talks to young scientists at the Korea Institute of Science and Technology in Seoul.

\title{
How to build science capacity
}

Eight leaders propose ways to boost research in their countries in the next decade.

\section{LIM CHUAN POH \\ Singapore: Build global networks}

Chairman of the Agency for Science, Technology and Research, Singapore

Last year, Singapore celebrated 20 years of government investment in science and technology. From 1991 to 2010, public expenditure on research and development doubled, from $0.4 \%$ to $0.8 \%$ of the gross domestic product. The number of research scientists in the public sector quadrupled, to nearly 13,000 .

One great success is our scholarship programme. Since 2001, it has enabled talented young Singaporeans to pursue education and training - from the undergraduate level to the postdoctoral - in leading universities and labs around the world. These students then return to Singapore to continue their

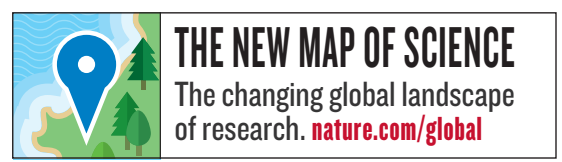

research for up to six years. Working abroad, they see first hand that a rich milieu is crucial to the pursuit of excellent science. They bring back new networks and collaborations.

For the past five years, we have also provided support for students and researchers from beyond Asia to participate in undergraduate research attachments and doctoral and postdoctoral stints in Singapore. So far, we have attracted more than 600 young researchers from more than 50 countries, including the United States, Brazil, the United Kingdom, Russia, Egypt, Sudan and Australia.

Many of these students have told me 
$>$ that they are grateful for the opportunity to come to Singapore and to work in a worldclass research environment in Asia. They often say that they were surprised by the excellent infrastructure, resource support and quality of science, as well as the presence of leading researchers from around the world. Many see Singapore as a gateway to the region and hope to stay in Asia to further their careers.

These young international students add to the research landscape a richness and diversity not otherwise possible in a country as small as Singapore. Eventually, they will also connect Singapore to research communities around the world.

\section{BERNIEFANAROFE South Africa: Think big}

\section{Director of the Square Kilometre Array, South Africa}

Building science capacity might not have seemed a priority after South Africa's transition to democracy in 1994. But in 1996, a government white paper underlined the importance of building competence in "flagship" sciences. Not to do this, it argued, would be to take the view "that we are a second-class nation chained forever to the treadmill of feeding and clothing ourselves".

The large facilities now available in southern Africa have already gone a long way towards creating a major centre for astronomy - the HESS (High Energy Stereoscopic System) $\gamma$-ray observatory, the Southern African Large Telescope and the MeerKAT radio telescope. The construction of the largest part of the Square Kilometre Array (SKA) in the region, with 2,700 dishes (the rest will be built in Western Australia), will make southern Africa a world leader in astronomy within a decade.

Mega-projects such as the SKA raise science's profile and draw in young people and resources. Big projects can be won if a country pulls together around a vision, as South Africans have in this case.

The idea of building the world's largest scientific instrument in Africa caught the imagination of people across the continent. The rest of the world was initially sceptical, but the outstanding work done to establish a protected site in South Africa's arid Northern Cape province and to build the MeerKAT precursor telescope won everyone over.

South Africa's bid for the SKA was developed over nine years, with enthusiastic support from government and the public, the media, the business community and the African Union. The site is scientifically excellent and the costs are low. An active radioastronomy community has grown around the project. Since 2005, more than 400 research, training and study grants have been awarded and five SKA university research chairs funded. Mutual-benefit agreements made with international technology companies recognize the quality of our young scientists and engineers through joint research.

The brain drain is being reversed. Outstanding astronomers from around the world have come to teach and work in South Africa. More than 70 SKA grants have gone to students from other African countries. Many have returned home and started astronomy courses in places such as Madagascar, Mozambique, Kenya, Ghana and Mauritius.

Building the SKA will help to grow a critical mass of young people in Africa who have world-class science and technology skills, and who are committed to innovation.

\section{PATRICK AEBISCHER Switzerland: Build elite institutions}

\section{President of the Swiss Federal Institute of Technology in Lausanne, Switzerland}

Europe must reform its academic system. The region needs more world-class universities akin to Harvard University and the Massachusetts Institute of Technology in the United States. Such elite scientific institutions are vital for breeding talent and promoting innovation and economic competitiveness.

The most important step is to give bright junior scientists the independence they need to establish and develop their careers within Europe. They should not have to move to the United States, as my generation had to. A cross-continent tenure-track system should be developed to retain rising stars and build a European market for academics.

More top-tier graduate schools on a par with those at the UK universities of Oxford and Cambridge must be created to select and train the most promising young scientists. Competitive fellowships would attract talent from all over the world. Trans-disciplinary topics such as sustainability or technology management should be included in graduate courses to provide the broad background necessary for tackling society's pressing problems.

Good leadership and funding are crucial in building world-class universities. University governance procedures must be adapted to empower well-respected academics as leaders - it is no coincidence that the best institutions have prominent figureheads. University leaders must see fund-raising as a central task. As much as we Europeans cherish our precious state funding, we must bring in extra resources to achieve excellence.

Lively campuses are important assets to attract the best students. Building dormitories, facilities for sport and culture and technology parks alongside well-equipped research laboratories would reproduce the vibrant campus experience of elite US universities. European institutions should promote their multilingual and cultural heritages to attract the brightest students.

Such improvements are feasible by 2020 , as my institution has shown - we implemented many of these reforms in the past decade.

RAFAELCAMACHO
Spain: Boost
translation

\section{Chief executive, Genoma España, Spain}

Science, like everything in Spain, must adapt to the economic struggle. Increased investment over the past decade has raised the country to ninth in the global ranking of scientific productivity. The nation's 135,000 researchers generate 70,000 scientific papers a year. Spain must capitalize by translating that research into goods and services.

As chief executive of Genoma España, a public foundation entrusted by the Spanish government to drive biotechnology innovation, I was appointed in 2009 to design and launch InnoCash, a pilot programme for adding value to technologies through market assessment and innovation financing. Three years later, 36 ventures have been funded, half in biotechnology and health, the rest in nanomaterials, information technology and energy.

Any 'accelerator' programme has three drivers: technology, money and talent. Showcasing the first was easy - we promoted patented technologies and results to potential investors through an online marketplace, linking technology-seekers and problem-solvers.

Mobilizing private money for early-stage and high-risk ventures was more difficult. As an incentive, Genoma España offered part-refundable loans of $€ 14$ million (US\$18.2 million); ultimately, two-thirds (€25 million) of the total funding came from private companies. As InnoCash proves, a modest public investment - just $10 \%$ of the total after seed grants are repaid — can accelerate technology business.

The most challenging aspect was finding skilled people to lead the ventures. We need to identify, train and motivate 'innopreneurs' who have technical knowledge, managerial skills and a risk-taking attitude. 


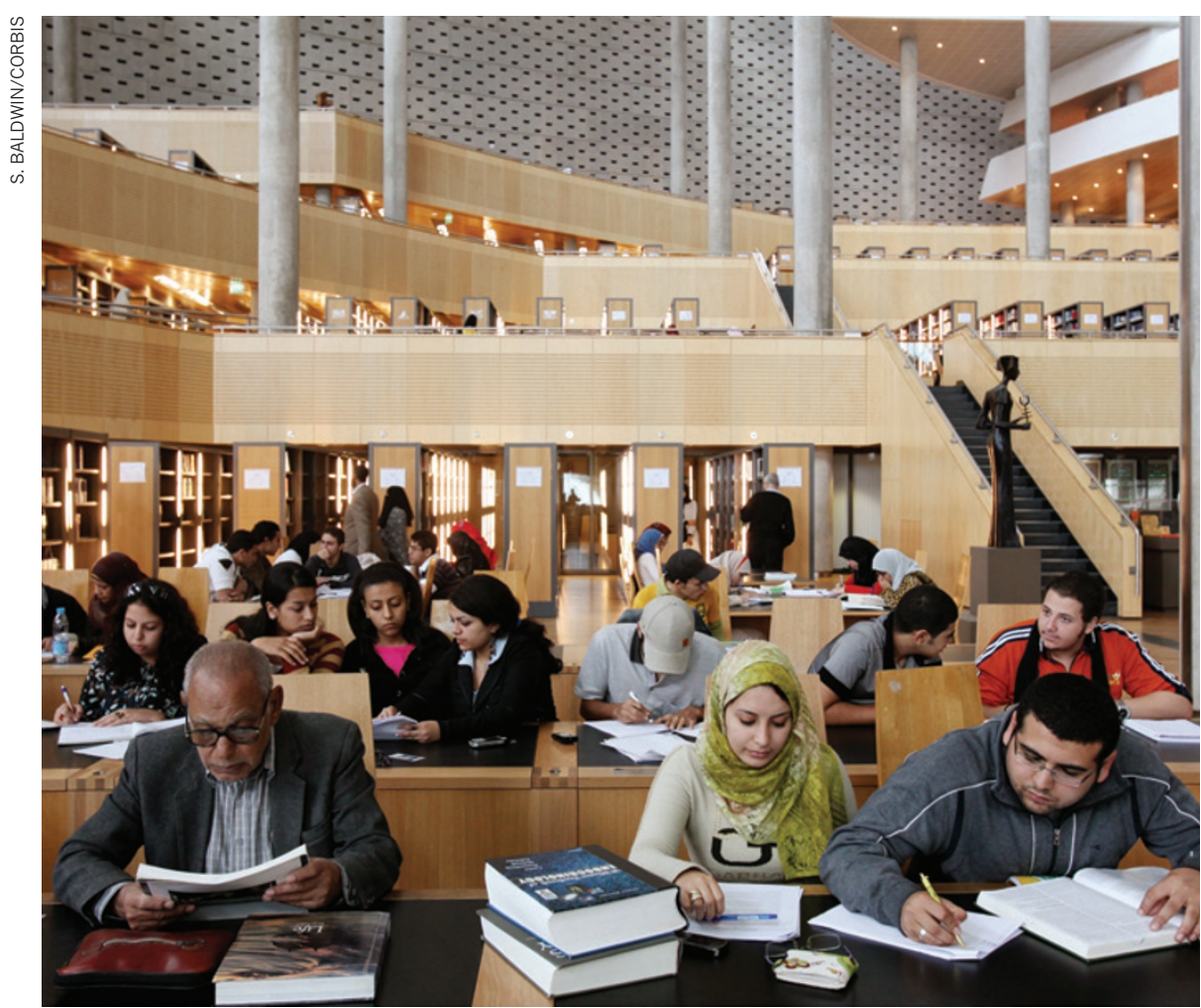

Egypt's Library of Alexandria is supervising the spread of online science courses in Africa.

In 2013, a single Research State Agency is due to launch, streamlining funding allocations. We must make scientific careers in Spain more attractive - through better contracts, improved recognition and more provision for researcher mobility. And we must support translational research, so that the benefits of Spanish science flow to society.

\section{ISMAIL SERAGELDIN Egypt: Share knowledge online}

\section{Director, Library of Alexandria, Egypt}

Africa produces less science than it could. Its home-grown innovations are not being nurtured by governments. Bottom-up initiatives are needed. We must use new technologies to empower those promoting science in the poorest countries. I am involved in two such projects.

One is the Science Supercourse, a collection of more than 170,000 PowerPoint lectures available for free on the Internet (see go.nature.com/hlksfr). The project is the brainchild of Ron Laporte, an epidemiologist at the University of Pittsburgh in Pennsylvania, in collaboration with the World Health Organization and the Library of Alexandria. It is supervised by Laporte along with Gil Omenn, a biomedical scientist at the University of Michigan in Ann Arbor; Vint Cerf, vice-president at Google in Mountain View, California; and myself.

Our lectures - designed by Nobel laureates as well as young assistant professors - distil the latest knowledge in a field in an accessible way. In epidemiology and public health alone, some 60,000 people have used them to reach 1 million students in more

The second project - a virtual help desk for researchers using the Supercourse is still in gestation. Overseen by the same team, it will give researchers in developing countries, particularly in Africa, guidance on research methods and statistics so that they can conduct, evaluate and publish research in international journals. By assisting scientists at the outset and during analysis, such a programme could markedly improve productivity.

Although the private sector has used help desks for decades, the concept has not, to our knowledge, been used to provide external support to individual scientists in their research. Learning from private industry, we intend to begin with a prototype in epidemiology and health, and later expand to other disciplines.

We have already collected and placed in the Supercourse repository many lectures and books as well as software related to research methods and statistics (see go.nature.com/oqfrzg). We invite scientists to add materials and to use what is available. than 170 countries.
NIKOLAY SUETIN Russia: Seed regional science

\author{
Director of Science and Technology, \\ IT Cluster, Skolkovo Foundation, \\ Russia
}

Half of Russia's scientists left after the political crisis of the 1990s. Since then, the country has had no scientific plan. Research resources have been misdirected and productivity has dropped, from about $3 \%$ of the total papers published globally in 1995 to less than $2 \%$ in 2010 .

Changes in the past decade have been more positive. The Russian government has increased the funding of scientific research from 77 billion rubles in 2006 to 323 billion rubles (US $\$ 10.4$ billion) in 2012. More is needed to overcome the prolonged deterioration of research in Russia and to move to an innovation-led economy.

Russia's share of high-technology products is now only $0.8 \%$ of the world market. A gap between pure and applied research is holding innovation back. Entrepreneurs, who turn intellectual property into products, are almost absent in Russia.

The Skolkovo Foundation - a government project that aims to build a Silicon Valley environment in Russia (see go.nature. com/tjzgdi) - bridges the divide between science and industry by supporting the creation of innovative companies.

One of Skolkovo's first success stories is Rock Flow Dynamics (RFD; www.rfdyn. com), a company that develops software for the petroleum industry. Founded in 2005 by three Moscow mathematics and physics graduates, in 2010 RFD attracted an investment of $\$ 2$ million from technology fund Intel Capital. Today, RFD sells product licences to oil and gas companies around the world.

Regional growth in science is badly needed. Most research is concentrated in the large cities of Moscow, St Petersburg, Tomsk and Novosibirsk. Cooperation between universities and local governments can benefit both, as at the South Ural State University in Chelyabinsk, where a powerful supercomputer centre has been created. Steps to improve researcher mobility, perhaps through competitive programmes such as the 2010 'megagrant' effort to set up a series of elite labs, would boost science across the nation.

With limited money, the Russian Federation must pick priority research areas. Information technology is one. The mathematical sciences have been strong historically, and as local IT companies such as Yandex, Kaspersky Lab and Parallels show, Russia could become a global leader. In the past 


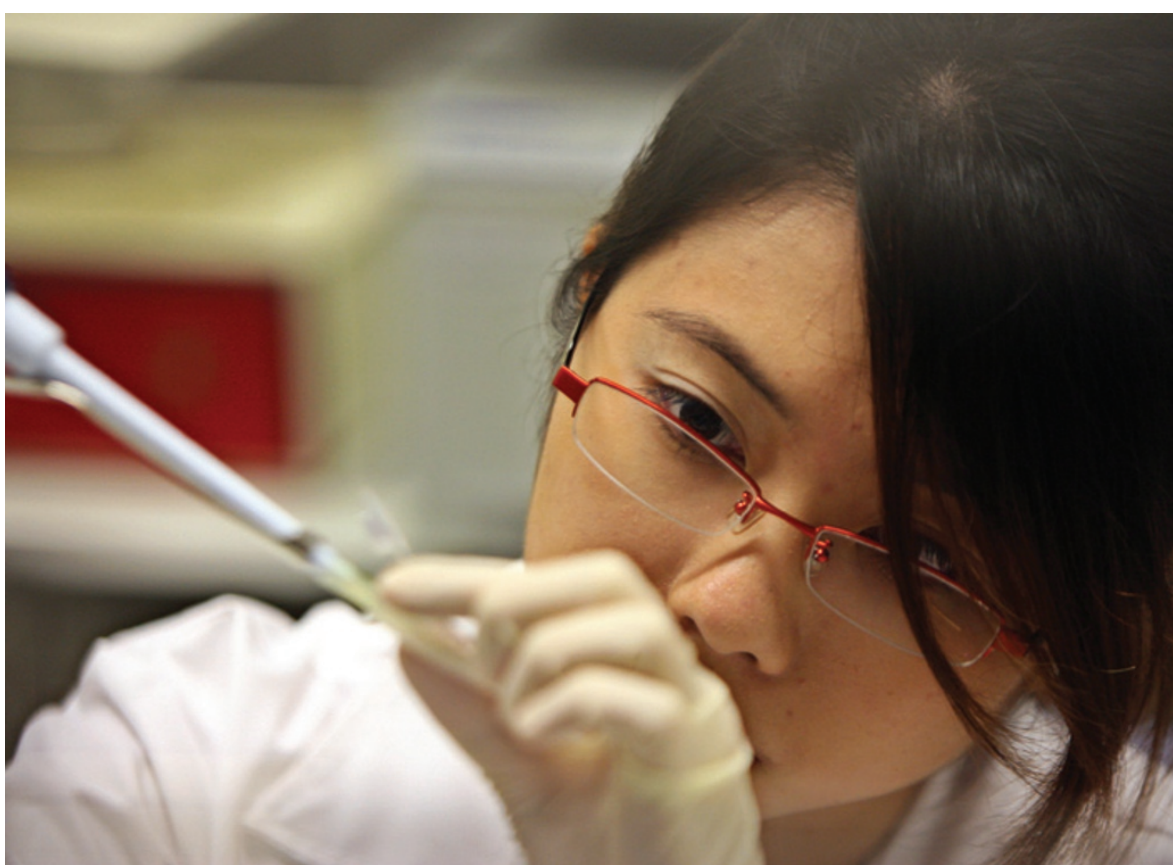

Singapore's scholarship programme has been building international links since 2001.

ten years, international giants IBM, Boeing and Siemens have created research centres in Russia.

Bureaucratic barriers that raise the cost of research, such as customs tax for imported scientific materials, must also be removed. With these steps, Russia can regain the position in global science that it deserves.

CARLOS HENRIQUEDE BRITOCRUZ

\section{Brazil: Reward quality}

\section{Science director, São Paulo Research Foundation (FAPESP), Brazil}

In the past 30 years, Brazil has built a broad science base in its universities, research institutes and industry. In 2011, the nation produced more than 12,000 doctoral students and 35,000 articles in international scientific journals. Growth has been impressive. But the system as a whole lags behind in quality and impact. On average, citations of Brazilian authors were the same in 2011 as in 1994: at 65\% of the world average.

Boosting Brazilian science requires enhancement of the quality and the social, economic and intellectual impact of research. Reviewers, institutions and agencies still overvalue quantity — of articles or of students. Quality must be better recognized and rewarded in academic careers

and in the selection of research-funding proposals.

Brazil's government must develop a plan to support around a dozen universities in executing excellence programmes that would propel institutes to among the 100 best in the world within a decade. Such programmes would improve academic governance, raise standards, encourage globalization of research projects and support worldwide searches for the best faculty members, postdocs and students.

The country already has highly selective universities that could become world class. The three state universities in São Paulo and the Federal University of Rio de Janeiro, for instance, admit on average only 1 in 20 graduate students who apply. In medicine and engineering, it can be 1 in 100 . Universities across

\section{“Developing international connections is crucial to raising research standards."}

Brazil should apply more stringent criteria for selecting graduate students and reviewing faculty members.

Developing international connections is crucial to raising standards. Brazilian scientists should collaborate and publish more with researchers from world-class institutions abroad. Funding agencies should use more international peer reviewers in assessing proposals.

Researchers need greater institutional support - including grant-management offices - as well as better links to government, business and non-governmental organizations. Systems for university governance should promote academic values and merit above petty politics and cronyism. Universities should have effective autonomy.

Improving basic education, stimulating young people to seek scientific careers and better distributing the scientific enterprise across the country are also essential to Brazil's development. Obtaining these goals and expanding the base of the system does not preclude raising academic standards at the top.

\section{JUNE SEUNG LEE South Korea: Back blue-skies work}

President, Korea Institute of Science \& Technology Evaluation and Planning (KISTEP), South Korea

From rubble to research, few nations have changed as rapidly as South Korea. Half a century after devastating wars, the country is now a member of the Organisation for Economic Co-operation and Development and hosted the G20 summit in Seoul in 2010. Eagerness for learning and investment in science and technology drove this rise.

Policy-makers recognize that sustaining prosperity will take more than mimicking high-tech products, as in the past. South Korean scientists should contribute to the creation of basic knowledge by investing in blue-skies research.

In the past decade, the South Korean government has doubled its budget for basic research — to about US\$5.4 billion in 2012 — and has initiated programmes to build infrastructure and to double the number of researchers. The number of papers published by South Korean scientists has tripled since 2000.

The government is taking a big risk: there is no guarantee that breakthroughs in fundamental research will bring returns. But, having experienced the benefits of sciencedriven development, South Koreans are ready to return knowledge to others.

The Institute for Basic Science (IBS), headquartered in Daejeon, was launched in May and, among other projects, will construct a heavy-ion accelerator costing about $\$ 460$ million. With state-of-the-art facilities, and by attracting at least 50 internationally renowned scientists as project leaders (ten are already in place), the IBS will become a world-class research and development complex.

To further strengthen our science base, we must support creativity and reduce bureaucracy. Young, inventive South Korean scientists must be able to secure positions at home, so that those with passion and ambition need not go abroad. 